\title{
Reducing Blood Culture Contamination Rates: Experiences of Four Hospital Systems
}

Diane C. Halstead - Robert L. Sautter - James W. Snyder •

Arthur E. Crist · Irving Nachamkin

Received: February 14, 2020 / Published online: April 30, 2020

(C) The Author(s) 2020

\section{ABSTRACT}

Introduction: Blood cultures (BCs) frequently become contaminated during the pre-analytic phase of collection leading to downstream ramifications. We present a summary of performance improvement (PI) interventions provided by four hospital systems and common

Digital Features To view digital features for this article go to https://doi.org/10.6084/m9.figshare.12123645.

D. C. Halstead

Division of Infectious Disease Diagnostic Laboratory Service, Southeastern Pathology Associates at Baptist MD Anderson Cancer Center, Jacksonville, FL, USA

R. L. Sautter

Department of Microbiology, Carolinas Pathology Group, Charlotte, NC, USA

J. W. Snyder

Division of Microbiology and Molecular

Diagnostics, University of Louisville, Louisville, KY, USA

A. E. Crist

Department of Laboratory Services, York Laboratory Associates at WellSpan Health System, York

Hospital, York, PA, USA

I. Nachamkin $(\bowtie)$

Perelman School of Medicine, Department of Pathology and Laboratory Medicine, Hospital of the University of Pennsylvania, University of

Pennsylvania, Philadelphia, PA, USA

e-mail: nachamki@pennmedicine.upenn.edu factors that contributed to decreased blood culture contamination (BCC) rates.

Methods: Each hospital independently formed a multidisciplinary team and action plan for implementation of their intervention, focusing on the use of educational and training tools. Their goal was to significantly decrease their BCC rates. Pre- and post-intervention data were compared during the sustainment period to determine their success.

Results: All hospitals met their goals of postintervention BCC rates and with most achieving and sustaining BCC rates $\leq 1.0-2.0 \%$.

Conclusion: Our report highlights how four hospitals independently achieved their objective to decrease their BCC rate with the support of a multidisciplinary team. We propose a benchmark for BCC rates of 1.5 to $<2.0 \%$ as achievable and sustainable.

Keywords: BCC benchmark; Blood culture contamination (BCC); Interventions; Multidisciplinary team; Performance improvements 


\section{Key Summary Points}

\section{Why carry out this study?}

Blood cultures are one of the most common tests performed for evaluation of patients with suspected bloodstream infections.

False-positive blood cultures, i.e., contaminated cultures, result in delayed diagnosis, unnecessary use of antibiotics, and additional health care costs.

\section{What was learned from the study?}

Blood culture contaminations were significantly reduced at four different hospital systems with a variety of approaches.

Laboratory-driven, multidisciplinary teams can devise a number of little to no cost interventions to drive down blood culture contamination rates.

We propose a benchmark of 1.5-2.0\% contamination rates that are achievable and sustainable.

\section{INTRODUCTION}

Blood cultures (BCs) are one of the most common tests performed for the evaluation of patients with suspected bloodstream infections. Numerous studies show that the false positivity rate of BCs, i.e., contaminated BCs, varies across institutions, ranging from $0.6-12.5 \%$ [1]. Falsepositive BCs may have negative consequences for patients including delayed diagnosis, unnecessary use of antimicrobial agents, increased length of hospitalization, additional laboratory testing, and increased overall healthcare costs [2-6]. Similar issues are apparent in the pediatric population with high BC contamination (BCC) rates and downstream effects [7]. Even though there have been several studies and meta-analyses highlighting interventions that have successfully reduced false-positive results [1, 8-17], institutions continue to face unacceptable BCC rates. Here, we report experiences of four major US hospital systems that successfully reduced their high rate of BCC with the introduction of a multidisciplinary change team, and comprehensive and creative educational programs, along with data sharing, training, retraining, and a plan to sustain reduced $\mathrm{BCC}$ rates.

Results of BCC interventions at Hospital A and $\mathrm{C}$ have been published in part [18-21].

\section{METHODS}

Four hospital systems (A-D) independently planned an intervention(s) to reduce BCC that was specific for their facility based on assessment of historic BC surveillance data, review of their processes, and compliance with their hospital policies. These plans were spearheaded by a collaborative, multidisciplinary team of stakeholders to lower their pre-intervention BCC rates. Per each institution's BC policy, 2\% chlorhexidine product and 70\% isopropyl alcohol were used for skin and BC bottle septum disinfection, respectively, followed by collection of two or more BC sets (i.e., one aerobic and one anaerobic bottle per set) from separate peripheral venipuncture sites, newly inserted IV catheters, or line draws when clinically indicated. Hospital $\mathrm{C}$ used a diversion tube along with skin disinfection when collecting BCs. Blood culture diversion tubes divert the first $1-2 \mathrm{ml}$ of blood to remove potential skin contaminants from entering the BC bottle [22]. All institutions used BD BACTEC ${ }^{\mathrm{TM}}$ Blood Culture media (BD, Sparks, MD), and inoculated BC bottles were incubated and monitored using the automated BD BACTEC ${ }^{\mathrm{TM}}$ FX system. All hospitals complied with the College of American Pathologists certification requirement to perform BCC surveillance and determine their contamination rates $[8,23]$. A standard definition of a contaminant due to skin flora was used at each institution, i.e., coagulase-negative staphylococcus, Bacillus species, not B. anthracis., Corynebacterium spp., Cutibacterium spp., viridans group streptococcus, and Micrococcus 
spp. in a single BC bottle or set, out of two or more sets within $24 \mathrm{~h}$ of collection [8, 17, 23]. At least two sets (i.e., 4 bottles) had to be obtained to define BCC. Hospital D also included saprophytic Neisseria sp. and Moraxella sp. in their definition of a contaminant. The institutions' BCC rate was determined by the number of contaminated cultures during a given time divided by the total number of cultures performed during the same given time. Hospitals $\mathrm{A}$ and $\mathrm{B}$ were able to identify individual collectors using codes or names to establish who needed retraining because of repeat BCC. Hospitals $\mathrm{C}$ and $\mathrm{D}$ monitored contamination by location where the BCs were drawn. BC surveillance data were acquired through their information technology (IT) system and shared on a monthly basis with key stakeholders (e.g., Infection Control, Pharmacy \& Therapeutic and Antimicrobial Stewardship committees, Emergency Department (ED), and phlebotomy manager and staff except for Hospital B who collected data manually and Hospital $\mathrm{C}$ who shared information on a quarterly basis.

Table 1 lists hospitals A-D, their demographics, phlebotomy staff, and annual number of BCs processed.
Table 2 identifies the elements of each phase of their intervention led by a multidisciplinary team. Initially, the leadership team assessed historical BCC surveillance data, their current process, where the intervention should occur, and, at some institutions, other issues such as staffing and length of the intervention. Subsequently, they developed an action plan for education and training based on their hospital's approved BC collection policy. Finally, they reviewed results comparing their pre- and postintervention data, key factors that contributed to a successful intervention, and what worked and what did not as part of their sustainment plan.

For statistical analysis, Fisher's exact test was used to compare BCC rates from one time period to another (GraphPad Prism version 7, GraphPad Software, San Diego, CA).

\section{Compliance with Ethics Guidelines}

Each analysis performed by Hospitals A-D was performed as part of ongoing quality assurance programs to monitor BCC rates. As such, these analyses were considered exempt by each respective Institutional Review Board.

Table 1 Demographics of four hospital systems performing independent interventions to reduce blood culture contamination

\begin{tabular}{lllll}
\hline & Hospital A & Hospital B & Hospital C & Hospital D \\
\hline $\begin{array}{l}\text { Healthcare (HC) } \\
\text { type }\end{array}$ & $\begin{array}{l}\text { Academic } \\
\text { Integrated HC system } \\
\text { (IHCS) }\end{array}$ & $\begin{array}{c}\text { Academic community HC } \\
\text { system }\end{array}$ & Academic IHCS & $\begin{array}{c}\text { Teaching } \\
\text { community }\end{array}$ \\
For profit & No & No & & IHCS \\
Bed number & 1229 & 350 & No & No \\
Patient & Adult & Adult & 788 & 580 \\
population & Pediatric & Nursery, NICU & Adult & Adult \\
Phlebotomy & Nursing $70 \%$ & Lab 95\% & Nursing and lab, hospital & Nursing $45 \%$ \\
& Lab 30\% & Nursing 5\% & dependent & Lab 55\% \\
BC/Year & 72,000 & 16,000 & 46,934 & 31,840 \\
\hline
\end{tabular}


Table 2 Common elements found in process improvement plans designed independently by four US healthcare systems

Elements of interventions

Assessment phase

(1) Multidisciplinary team

(2) Historic data

(3) BC process review

(4) Hospital wide target

(5) ED target

(6) Intervention period

(7) Goal as low as possible

Action plan for intervention phase

Collector codes or ID on BC bottles

IT captured data

Monthly* BCC surveillance reports shared with stake- holders and feedback

Education/training

(1) Online E-learning and exam

(2) Video

(3) Skills fairs, nursing days, boot camp

(4) Written guidelines \&/or collection policy

(5) Observation

(6) Training by nurse educators/microbiologist/infection preventionist/ lab phlebotomists for one-on-one and trainthe-trainers, lectures

(7) Engagement of staff

(8) Real-time BCC reports to nurse managers for counseling and retraining

(9) Accountability

Sustainment plan

(1) Continued monitoring of BCC and data sharing

(2) Retraining of collectors with repeat BCC

(3) Quarterly retraining
Hospital

A

$\times$

$\times$

$\times$

$\times$

2007-2014

2014-2018

2014-2017

2006-March 2007

$\times$

$\times$

$\times$

$\times$

$\times$

$\times$

$x^{2}$


Table 2 continued

\begin{tabular}{|c|c|c|c|c|}
\hline Elements of interventions & $\begin{array}{l}\text { Hospital } \\
\text { A }\end{array}$ & Hospital B & $\begin{array}{l}\text { Hospital } \\
\text { C }\end{array}$ & Hospital D \\
\hline $\begin{array}{l}\text { (4) Continual education and training through at least yearly } \\
\text { videos, skills fair/nursing days, and/or online E-learning } \\
\text { exercises }\end{array}$ & $x$ & $x$ & $x$ & $x$ \\
\hline (5) Component of competency program & - & - & $\times$ & $x$ \\
\hline (6) Component of annual review & - & $x$ & - & - \\
\hline (7) Quality awards & $x$ & - & - & - \\
\hline $\begin{array}{l}\text { (8) Support from nurse managers, infection preventionists, } \\
\text { administration }\end{array}$ & $x$ & $x$ & $x$ & $x$ \\
\hline
\end{tabular}

\section{RESULTS}

\section{Hospital A}

In 2007, based on their monthly BCC data, Hospital A had BCC rates of $6.0-7.0 \%$ in four of their hospitals and $>9.0 \%$ in their main hospital ED. An educational intervention to reduce their BCC rate was initially introduced in 2008 and 2010 in their main 1229-bed hospital inpatient (IP) units and ED, respectively, and later in the other three hospitals. The IP intervention was approved by the nursing education council and fostered by a collaborative multidisciplinary committee, i.e., the Infectious Disease Coordinating Committee co-chaired by the microbiology director and infectious disease pharmacist. The intervention included (1) trainthe-trainer, one-on-one training, and educational materials that were presented to the staff by the nurse educator and nursing and laboratory staff on their nursing units and during Nurse Education Day, (2) a required yearly review of an online E-learning tool, (3) an approved video prepared in September 2009 by the Laboratory Quality Team (multidisciplinary team) based on their collection policy and placed on the internet for required viewing and competency testing, and (4) collector codes for laboratory phlebotomists to track their BCC rate. Originally, they were unable to provide codes for nurse phlebotomists who collected most BCs. Once these codes had been enabled, a BCC report could then be shared with leadership so they could follow up real-time with collectors for retraining on a case-by-case basis for those laboratory phlebotomists with repeated BCC.

The ED intervention was initiated by physicians, phlebotomists, and medical technologists and supported by their vice president, chief nursing executive, and chief medical officer. In January 2010, (1) RNs and ED technicians (EDTs) responsible for collecting most BCs were trained, (2) collector codes were created for each phlebotomist to record on BCs they collected to track and train repeat BCC offenders just like the laboratory phlebotomists on the IP units, (3) "Boot Camp" was created to educate collectors on correct BC collection techniques with emphasis on skin disinfection, and (4) EDTs were required to perform ten phlebotomies in the presence of an ED specialist before they were allowed to draw BCs without observation. Every time they were responsible for a contaminated $\mathrm{BC}$, re-education and observation of their phlebotomy technique were required. Both RNs and EDTs were also required to participate in an annual refresher program for proper BC collection. Compared with 2008, BCC rates for the ED 
A

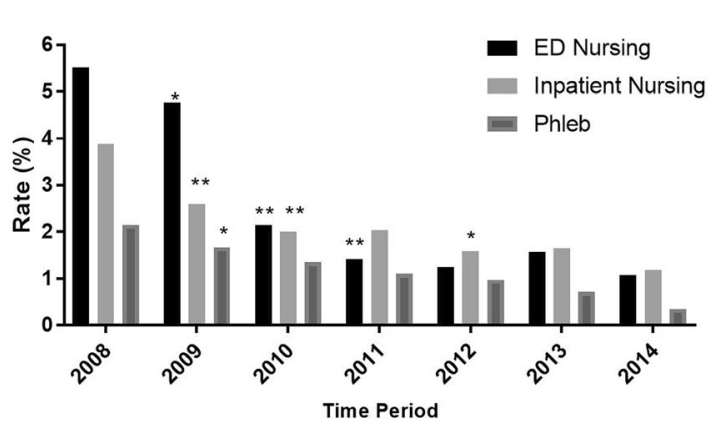

$p$ values from preceding $B C C$ rate for the category ${ }^{* *} p<0.005{ }^{*} p<0.05$

C

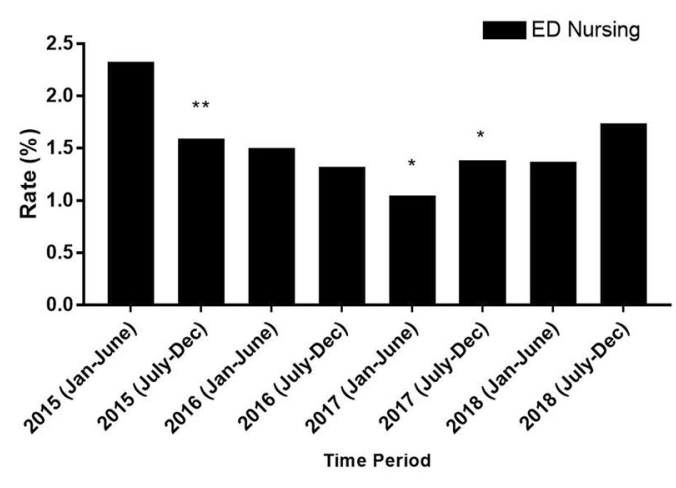

$p$ values from preceding $B C C$ rate for the category ${ }^{*} p<0.05{ }^{* *} p<0.005$

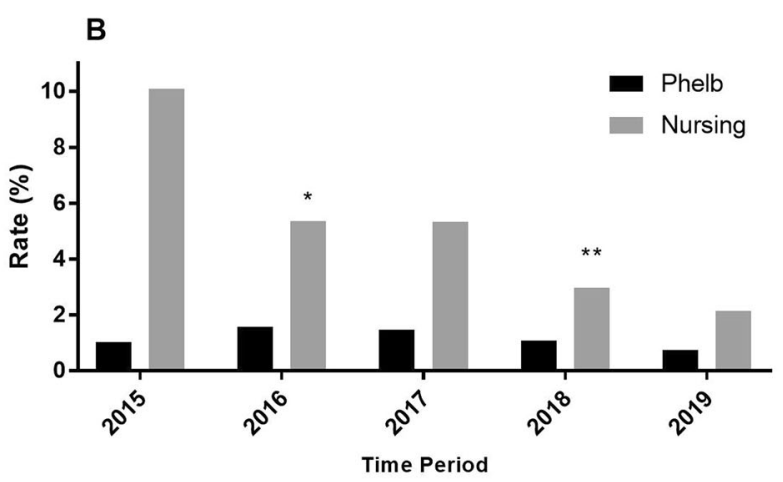

$p$ values from preceding $B C C$ rate for the category ${ }^{*} p<0.001{ }^{* *} p<0.005$

D

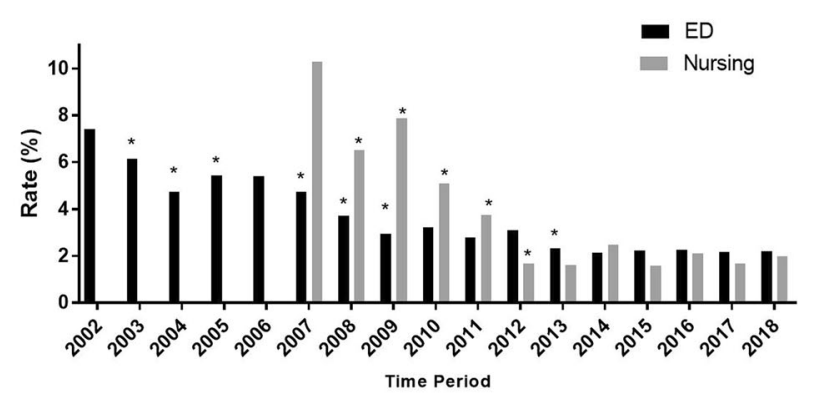

$p$ values from preceding $\mathrm{BCC}$ rate for the category ${ }^{*} \mathrm{p}<0.01$

Fig. 1 Decrease in blood culture contamination over time in four hospital sytems following interventions. For each hospital shown in this figure, $p$ values are indicated when significant for comparison of BCC rates from the previous rate

showed steady reduction from 5.52 to $1.42 \%$ in 2011 and leveled out consistently below 1.6\%. (Fig. 1, Hospital A).

Sustainment of success in decreasing and maintaining BCC rates $<1.6 \%$ overall on the nursing units was attributed to manager, nursing, and phlebotomist accountability, ongoing education and training, use of the online BC collection video, and celebrations using Quality Awards for successful achievement. Overall success in adhering to the BC policy in the $\mathrm{ED}$ was attributed to accountability, education using the BC collection video, and "Boot Camp." By 2013 and 2014, the rates for IP and
ED nursing showed essentially no difference in BCC rates and were able to maintain low rates.

\section{Hospital B}

In 2012, a private management company was hired by Hospital B that resulted in elimination of their laboratory phlebotomy team and 50\% of the laboratory positions. Nursing staff were assigned to collect most BCs. Despite detailed education, nursing BCC rates increased to $12.0-15.0 \%$, while laboratory phlebotomy with few BC draws also increased to $>8.0 \%$. In 2014, the Director of Microbiology provided 
justification to reinstate the laboratory phlebotomy team with the same number of phlebotomists as they had initially, although it took 2 years for the team to be fully staffed. This team was responsible for all BC collections except for patients in their Bone Marrow Transplant Unit and line draws collected by nursing. A performance improvement (PI) program was developed by a multidisciplinary team spearheaded by the microbiology director and infection preventionist beginning in 2014 to reduce nursing and laboratory BCC rates. They developed a (1) comprehensive education and training program on proper $\mathrm{BC}$ collection techniques along with (2) an educational video for the newly reformed laboratory phlebotomy team.

BCC gradually decreased to $2.6-3.0 \%$ over the first 2 months of 2014 when the laboratory phlebotomy team was re-introduced. From 2015 through 2019, phlebotomy BCC rates fluctuated slightly between approximately $<1 \%$ to $1.6 \%$ (Fig. 1, Hospital B).

Success in decreasing BCC rates for peripherally collected specimens was attributed to using a formal education program given by the microbiology director, infection preventionist, laboratory phlebotomy team, use of a video based on best practices for BC collection, and the support of the healthcare management company for re-establishing a laboratory phlebotomy team. Sustainment was associated with quarterly retraining and monitoring. Individual contamination rates also became part of the collector's annual performance review.

\section{Hospital C}

Hospital C had a process since 2014 whereby BCC data were downloaded monthly from IT; line listings were prepared by the microbiology manager, reviewed by a faculty director who identified which draws represented BCC based on skin flora in a single set within $24 \mathrm{~h}$, and then forwarded to the laboratory medicine data analyst to generate quality assurance (QA) reports. Quarterly QA reports were then sent to the ED quality manager who determined whether an intervention was needed in the ED to reduce BCC. From July-September 2014, the monthly BCC rates in the ED steadily increased from $2.21 \%, 3.24 \%$, to $3.92 \%$, respectively. A PI project led by the ED Quality Group, ED nursing, and clinical microbiology laboratory leadership was introduced to focus on lowering the BCC rates. Based on observed trends, the team developed a (1) multi-prong intervention in the ED including education with written guidelines, (2) review of contamination data, (3) additional training and phlebotomy observation, and (4) development of new competencies for all ED nursing staff.

Following implementation of the ED PI program, the BCC rate dropped to $2.09 \%$ in October $2014(p<0.003$; Fig. 1) Hospital C showed BCC rates in 6-month intervals through December 2018. During the 48 months of monitoring, there were 7 months where BCC rates were $>2 \%(2.04-2.23 \%)$ and 25 months when rates were $<1.5 \%(0.78-1.47 \%)$. For 12 of those months, they were approximately $1 \%$ (range $0.78-1.14 \%$ ). BCC reports continue to be generated each quarter, and results are shared with the ED, Pharmacy \& Therapeutics (P\&T) Antibiotic Subcommittee, and all hospital units. Success was attributed to their competency program, continuous education, and quarterly retraining.

\section{Hospital D}

The ED staff initiated a formal project starting in December 2006 to address high contamination rates, decrease BCC as low as possible, and answer the question "Is a dedicated phlebotomy team the answer?" They requested collectorspecific information regarding BCC rates. Trending by collector, completed over a 6-month period, showed many of the $125 \mathrm{ED}$ nurses and ECTs who collected the majority of $\mathrm{BCs}$ in the ED had repeated BCC. Additional issues included adding new short-term and permanent staff were on a regular basis. A multidisciplinary team was formed including the ED charge nurse, RN, LPN, ECTs, nursing clinical leaders, director and manager of microbiology, Lab Service staff, core laboratory management team, members of the ED-Lab 
Liaison Committee, Performance Improvement (PI) Specialist, clinical educator, and Clinical Research Director and statistician. The following interventions were implemented: (1) collectors with higher than expected contamination rates due to the presence of skin flora were educated and retrained on proper BC collection, and (2) additional education and inservices were provided in 2007-2008 for the ED nursing staff attending Grand Rounds to reduce BCC, and (3) in 2011, viewing a video that showed proper collection of BC collections was required as part of annual competency for individuals collecting BCs as well as any new employees.

Since 2001, contamination rates were monitored by location and collector. Those collectors with $\geq 3.0 \%$ BCC rates were re-educated and trained. In 2002, the ED nursing and ECT BCC rate dropped from $7.4 \%$ to a low rate of $2.2 \%$ in 2018 (Fig. 1, Hospital D), whereas the laboratory phlebotomy team (not shown) was 2.3\% and dropped to a low rate of $<1.0 \%$. Success was attributed to the engagement of ED staff, educational in-services, use of training videos, standardized retraining of ED staff based on their BC policy, and demonstrated competency. A dedicated laboratory phlebotomy team was not pursued because of the ED's successful intervention.

Historical BC data were available at Hospital D starting in 2002 with rates of $7.4 \%$ for BCs collected by ED nurses (RN, LPN) and emergency care technicians (ECT) compared with $2.3 \%$ by dedicated laboratory phlebotomists. Nursing draws were primarily line draws that were improved with education and the institution of training videos and feedback. In addition, an attempt to collect a peripheral BC was required along with a line draw approved by an ordering physician. This lowered the contamination rate to $<3 \%$ for line draws between 2007 (> 7\%) and 2012 (1.2\%). Also, the total number of line draws decreased significantly over time from 1497 per year in 2007 to 303 per year in 2018. Results were reviewed by the Nursing Practice Counsel to pursue a hospital-wide intervention.

\section{DISCUSSION}

Laboratories are challenged to provide a valuebased service that includes accurate, rapid, and clinically meaningful results that lead to improved patient care while supporting their antimicrobial stewardship program. Several studies and meta-analyses have described successful interventions using dedicated phlebotomy teams, sterile gloves and processes, collection kits, and diversion devices to decrease BCC rates [1, 5, 8-10, 12, 14-17, 24]; however, we still do not have one intervention or combination of interventions that has been universally accepted to decrease BCC rates $[10,11,14]$. Perhaps we need national regulations by the Center for Medicare and Medicaid Services (CMS) as part of their Quality Measurement Program to develop a requirement for all healthcare facilities involved in BC collection to develop a BC Stewardship Program [25].

What is an acceptable BCC rate? Many institutions use $\leq 3.0 \% \mathrm{BCC}$ as their benchmark for an acceptable BCC rate, although there does not appear to be documentation as to where or how this level was derived $[5,8,26]$. It is clear from the results obtained from our four hospital systems and from the literature [14] that BCCs of much less than 3\% are achievable and sustainable by both laboratory and nursing employees collecting BC samples. Based on our results, we propose a new achievable and sustainable BC contamination rate benchmark of 1.5 to $<2 \%$.

Our report is based on results obtained from four independent studies performed by major healthcare systems representing $>166,774$ BCs per year collected predominantly from adults by nurses and phlebotomists. Although several intervention options, e.g., collection kits and sterile gloves, were introduced early on by Hospital A to lower their contamination rates, they did not experience sustained success until they utilized a multidisciplinary team approach to lower rates based upon education, feedback, accountability, and sustainable training to maintain rates significantly $<0.35-1.19 \%$ $[20,21]$. 
Another option that might have been helpful is the use of the TeamSTEPPS ${ }^{\mathrm{TM}}$ evidencedbased program developed by the Department of Defense and the Agency for Healthcare Research and Quality (AHRQ) and introduced in 1996 by CMS to provide guidance for successful interventions [27]. TeamSTEPPS ${ }^{\mathrm{TM}}$ has been implemented by healthcare professionals throughout the USA and internationally to: improve patient safety and health care teamwork skills. The program provides a toolkit for introducing a readiness assessment, detailed plan for training and implementation of an intervention, and sustainment of successes. Although the hospitals reported here did not use the TeamSTEPPS $^{\mathrm{TM}}$ toolkit, aspects of each phase of this program were used as in a previously reported study [16].

A key to the success of an improvement program is the development of a multidisciplinary change team as recommended in the TeamSTEPPS $^{\mathrm{TM}}$ program comprised of (1) an executive leader who provides the clout to bring about change and authority to allocate resources, motivate, and support the team, (2) clinical and technical champions who are knowledgeable, understand processes, have an interest in driving change, and can serve as instructors and coaches, and (3) front-line leaders who understand the organizational detail, can effect change, and oversee data collection and assure changes are measured [28]. Each of the four hospitals presented here developed their own plan based on resources and needs assessment for decreasing BCC, but all of them used a multidisciplinary team approach. An assessment of historical pre-intervention BCC surveillance data provided the necessary information for each hospital to set a goal to decrease contamination rates as low as possible, target where the intervention would occur, i.e., the ED or hospital-wide, and confirm the readiness of their target site based on staffing and other activities that might side track the intervention. Several publications have targeted the ED where BCC is frequently highest $[3,9,16,24,29]$. Two of the four reporting hospitals also targeted the ED (Hospital C and D), while the other hospitals took a wholehospital approach. Although we focused our attention on reducing BCC rates for peripherally obtained BCs, one of the centers, Hospital D, also addressed line draw BCCs (see Hospital $D$ results above).

Although there are no guidelines for the determination of line- or catheter-associated BCC, Hospital D was able to determine which BCs collected were from peripheral or line access. They used the same definition of blood culture contamination for both processes. After education, feedback, and limiting line draws, the contamination rates for line collection fell from $>7$ to $1.2 \%$ and were maintained at levels $\leq 2 \%$. In a meta-analysis performed by Snyder et al. [1], they found that typically, the contamination rates are much higher in line (catheter) collection than in venipuncture.

Often the collection through catheters offers advantages including reduced needle sticks, ease of collection, and patient comfort; also, for difficult collections, it offers a method to rapidly obtain BCs [30]. Recommendations for collections of line cultures include a collection of a second culture from a venipuncture site to compare growth to aid in determining true infections from contaminants [31]. The Infectious Disease Society of America supports this recommendation when collecting BCs from central lines [32]. The evaluation of critically ill and immunosuppressed patients is difficult. Clearly the specificity of line draws is lower than that of peripheral collections, and additional BCs are needed to determine a true bacteremia from contamination or line colonization $[10,33]$. Care must be taken in evaluating BC results that contain organisms associated with contamination. Upon reviewing results from BCs with coagulase-negative staphylococci by a team of infectious disease specialists, they concluded that as much as $85 \%$ of these isolates were contaminants [10, 32].

All locations were deemed ready for an intervention initiative to accomplish their goal. Each hospital followed an action plan for the implementation of their intervention using an approved BC collection policy as the foundation for their educational and training programs. Intervention success was measured by comparing pre- and post-intervention data. 
Whereas many studies highlight the use of collection kits, diversion devices, sterile gloves, processes, dedicated phlebotomy teams, etc., the successful experiences presented here by four major hospital systems are based on just a few key elements for changing the tide in each of their hospital systems without additional staff. We conclude by using continuous monitoring, appropriate feedback, accountability of collectors, and continued education, welltrained nurses and laboratory phlebotomists alike can achieve low BCC rates. The last and perhaps most important phase of implementing a successful intervention, and in the opinion of the authors the phase most often neglected, is the development of a plan for sustainment. Often hospitals experience success, albeit not long-lived. Without continual training, retraining, and updating the intervention, nurse and laboratory phlebotomists may become disengaged because of high work volumes and changes that overshadow their willingness to follow the BC policy without exception.

\section{LIMITATIONS}

Hospitals A-D all engaged in independent PI interventions based on their unique needs that reflect real-world experiences rather than participating in a single study at four sites. The results and recommendations refer only to peripherally drawn $\mathrm{BCs}$ and contamination rates.

\section{CONCLUSION}

We report the steps used by each of four hospital systems based on their resources and needs assessment to decrease their high BCC rates. From this information, we extracted aspects of each plan that were common to most if not all hospitals to establish a list of key factors contributing to a successful and sustained intervention. We propose a new benchmark for BCC of 1.5 to $<2 \%$, which is achievable and sustainable based on our experiences. Other healthcare facilities may find the plans and list of key factors useful in developing their own unique plan to achieve similar successes.

\section{ACKNOWLEDGEMENTS}

Contributing Members. Hospital A-John Ehlers, Video Expert, H. James Norton, PhD, Dickson Advanced Analytics and the Multi-disciplinary Team; Laboratory: Na'adir Drew, Phlebotomist, Susan Grissom, MT (ASCP), Manager of Laboratory Quality, Flow Kerns, CPT (ASCP), Supervisor of Phlebotomy, Patricia Meech, MT (ASCP), Microbiology Technologist, Robin Miller, MT (ASCP), Laboratory Quality, Anne Odell, MT (ASCP), Laboratory Quality, Barbara Oxford, MT (ASCP), Microbiology lead technologist, Dara Porter, CHS (ABHI), Laboratory Quality, and Andrew Smithen, MS MT (ASCP), Manager of Chemistry Laboratory; Nursing: Jennifer Bartlett, RN, Jeanette Cancellieri, RN, J. Dillard, RN, Robert Leonhardt, RN, MSN, Assistant VP of Nursing, K. Mason, RN BSN, Emergency Room Nursing, L. Murphy RN, Emergency Room Nursing, Grace Sotomyer, RN, DNP, Vice President/Chief Nurse Executive; Medical Staff: Drs. Jared Block, Pathologist, Stephen Colucciello, Emergency Room Director, Tyson Cook, Internal Medicine Resident, Randy Cordle, Pediatric Emergency Room Physician, Robert Heyer, Internal Medicine and Pulmonary Critical Care Physician, James Horton, Infectious Disease Director, James Hunter, Executive Vice President and Chief Medical Officer, Edward Lipford, Director of Pathology, Lewis McCurdy, Infectious Disease Physician, Brian Moore, Emergency Room Physician, Kevin Smith, Pathologist; Hospital B-Sarah M. Bishop, MSN, APRN, CCNS, CIC, Director, Infection Prevention and Control, Amy Nettle, Supervisor, Phlebotomy Team, Joyce Garr, Superviser of Microbiology; Hospital C-Mei Yu, Dan Danoski, Joshua Barnes, Jennifer Barger; Hospital D-Jackie Keely, RN, CEN, Rose Stike, Med, EMT-B, Dave Bankert MT (ASCP) and Sharon Wetzel MT (ASCP), Microbiology Laboratory Managers, June Wineholt, Glynnis Lowe, Jenny Bosley, RN, BSN, CEN, Steve 
Manzella, PhD, Clinical Director Core Laboratory, Tina Stover MT (ASCP), Administrative Director-Laboratory Services, Delores J. Spangler MT (ASCP), Phlebotomy Program Manager, Marc Pollack, MD, PhD, Amy Daugherty, MS; and others including members of the nursing, laboratory, IT, medical and administrative staff at the participating hospitals.

Funding. No funding or sponsorship was received for this study or publication of this article.

Authorship. All named authors meet the International Committee of Medical Journal Editors (ICMJE) criteria for authorship for this article, take responsibility for the integrity of the work as a whole, and have given their approval for this version to be published.

Disclosures. Diane C. Halstead, Robert L. Sautter, James W. Snyder, Arthur E. Crist, Jr, and Irving Nachamkin have no competing interests or financial disclosures to declare related to blood culture contamination. Irving Nachamkin is a member of the journal's Editorial Board. This research did not receive any specific grant from funding agencies in the public, commercial, or not-for-profit sectors. Diane Halstead's current affiliation is Global Infectious Disease Consultants LLC, Jacksonville Beach, FL. Robert L. Sautter's current affiliation is RL Sautter Consulting LLC, Lancaster, SC.

Compliance with Ethics Guidelines. Each analysis performed by Hospitals A-D was performed as part of ongoing quality assurance programs to monitor blood culture contamination rates. As such, these analyses are considered exempt by each respective Institutional Review Board.

Data Availability. All data generated or analyzed during this study are included in this published article.

Open Access. This article is licensed under a Creative Commons Attribution-NonCommercial 4.0 International License, which permits any non-commercial use, sharing, adaptation, distribution and reproduction in any medium or format, as long as you give appropriate credit to the original author(s) and the source, provide a link to the Creative Commons licence, and indicate if changes were made. The images or other third party material in this article are included in the article's Creative Commons licence, unless indicated otherwise in a credit line to the material. If material is not included in the article's Creative Commons licence and your intended use is not permitted by statutory regulation or exceeds the permitted use, you will need to obtain permission directly from the copyright holder. To view a copy of this licence, visit http:// creativecommons.org/licenses/by-nc/4.0/.

\section{REFERENCES}

1. Snyder SR, Favoretto AM, Baetz RA, Derzon JH, Madison BM, Mass D, et al. Effectiveness of practices to reduce blood culture contamination: a laboratory medicine best practices systematic review and meta-analysis. Clin Biochem. 2012;45: 999-1011. https://doi.org/10.1016/j.clinbiochem. 2012.06.007.

2. Bates DW, Goldman L, Lee TH. Contaminant blood cultures and resource utilization: the true consequences of false-positive results. JAMA. 1991;265: 365-9. https://doi.org/10.1001/jama.1991. 03460030071031.

3. De La Rubia-Orti JE, Verdu-Trescoli G, Prado-Gasco V, Selvi-Sabater P, Firmino-Canhoto J. Contamination rate of blood tests and its determining factors. Acta Paul Enferm. 2014;27:1-6. https://doi.org/10. 1560/1982-0194201400026.

4. Dempsey C, Skogland E, Muldrew KL, Garey KW. Economic health care costs of blood culture contamination: a systemic review. Am J Infect Contr. 2019;47:963-7. https://doi.org/10.1016/j.ajic.2018. 12.020 .

5. Doern GV, Carroll KC, Diekema DJ, Garey KW, Rupp ME, Weinstein MP, et al. A comprehensive update on the problem of blood culture contamination and a discussion of methods for addressing the problem. Clin Microbiol Rev. 2020;33:1-21. https://doi.org/10.1128/CMR.00009-19.

6. Gander RM, Byrd L, DeCrescenzo M, Hirany S, Bowen M, Baughman J. Impact of blood cultures drawn by phlebotomy on contamination rates and 
health care costs in a hospital emergency department. J Clin Microbiol. 2009;47:1021-4. https:// doi.org/10.1128/JCM.02162-08.

7. El Fehaly RA, Chatterjee J, Dowdy K, Stempak LM, Morgan S, Needham W, et al. A quality improvement initiative: reducing blood culture contamination in a Children's Hospital. Pediatrics. 2018;142:e20180244. https://doi.org/10.1542/peds.2018.0244.

8. Bekeris L, Tworek JA, Walsh MK, Valenstein PN. Trends in blood culture contamination. A college of American Pathologists Q-Tracks Study of 356 Institutions. Arch Pathol Lab Med. 2005;129:1222-5.

9. Bowen CM, Coleman T, Cunningham D. Reducing blood culture contaminations in the emergency department: it takes a team. J Emerg Nurs. 2016;42: 306-11. https://doi.org/10.1016/j.jen.2015.10.021.

10. Garcia RA, Spitzer ED, Beaudry J, Beck C, Diblasi R, Gilleeny-Biabac $\mathrm{M}$, et al. Multidisciplinary team review of best practices for collection and handling of blood cultures to determine effective interventions for increasing the yield of true-positive bacteremias, reducing contamination, and eliminating false-positive central line-associated bloodstream infections. Am J Infect Control. 2015;43:1222-37. https://doi.org/10.1016/j.ajic.2015.06.030.

11. Hall KK, Lyman JA. Updated review of blood culture contamination. Clin Microbiol Rev. 2006;19: 788-802. https://doi.org/10.1128/CMR.00062-05.

12. Harding AD, Bolling S. Reducing blood culture contamination rates in the emergency department. J Emerg Nurs. 2013;39:e1-e6. https://doi.org/10. 1016/j.jen.2012.10.009.

13. Park WB, Myung SJ, Oh M, Lee J, Kim NJ, Kim EC, et al. Educational intervention as an effective step for reducing blood culture contamination: a prospective cohort study. J Hosp Infect. 2015;91: 111-6. https://doi.org/10.1016/j.jhin.2015.04.022.

14. Proehl JA, Leviner S, Bradford JY, Storer A, Barnason $\mathrm{S}$, Brim C, et al. Clinical practice guideline: prevention of blood culture contamination (full version). Emerg Nurse Assoc (ENA) 2012:1-12.

15. Roth A, Wiklund AE, Paisson AS, Melander EZ, Wulit M, Crongvist J, et al. Reducing blood culture contamination by a simple informational intervention. J Clin Microbiol. 2010;48:4552-8. https:// doi.org/10.1128/JCM.00877-10.

16. Self WJ, Speroff T, Grijalva CG, McNaughton CD, Ashburn J, Liu D, et al. Reducing blood culture contamination in the emergency department: an interrupted time series quality improvement study. Acad Emerg Med. 2013;20:89-97. https://doi.org/ 10.1111/acern.120571.
17. Weinstein MP. Blood culture contamination: persisting problems and partial progress. J Clin Microbiol. 2003;41:2275-8. https://doi.org/10. 1128/JCM.41.6.2275-2278.2003.

18. Chen AI, Nachamkin I. Assessing patterns of blood culture utilization at a University Hospital. Abstracts of the ASM Microbe 2017, June 1-5, 2017. New Orleans, LA, Poster No. 246.

19. Chen AI, Bilker WB, Hamilton KW, O'Donnell JA, Nachamkin I. Blood culture utilization at an academic hospital: addressing a gap in benchmarking. Infect Control Hosp Epidemiol. 2018;39:1353-9. https://doi.org/10.1017/ice.2018.231.

20. Miller R, Cancelleri J, McCurdy L, Sautter RL. A multidisciplinary approach to lowering blood culture contamination rates. Abstracts of the Interscience Conference on Antimicrobial Agents and Chemotherapy 2011, September 17, 2011. Chicago, IL, Poster No. D-097.

21. Sautter RL. Multidisciplinary team to achieve low blood culture contamination rules in health care facilities. J Emerg Nurs. 2015;41:182-3. https://doi. org/10.1016/j.jen.201502.009.

22. Rupp ME, Cavalieri J, Marolf C, Lyden E. Reduction in blood culture contamination through use of initial specimen diversion device. Clin Infect Dis. 2017;65:201-5. https://doi.org/10.1093/cid/cix304.

23. College of American Pathologists (CAP). Blood culture contamination-QT2. Quality Management 2019 - QTRACKS. https://estore.cap.org/OA_ HTML/xxCAPibeCCtpItmDspRte.jsp?item= 445591\&sitex=10020:22372:US

24. Hall RT, Domenico HJ, Self WH, Hain PD. Reducing the blood culture contamination rate in a pediatric emergency department and subsequent cost savings. Pediatrics. 2013;131:e292-e297297. https:// doi.org/10.1542/peds.2012-1030.

25. Goodrich K, Garcia E, Conway PH. A history of and a vision for CMS quality measurement programs. Joint Commission J. 2012;38:465-70. https://doi. org/10.1016/S1553-7250(12)38062-8.

26. Wilson, ML, Mitchell M, Morris AJ, Murray PR, Reimer LG, Reller LB. Principles and procedures for blood cultures: approved guideline. CLSI document M47-A. Wayne PA 2007.

27. King HB, Battles J, Baker DP, Alonso A, Salas E, Webster J, et al. TeamSTEPPS ${ }^{\mathrm{TM}}$ : Team strategies and tools to enhance performance and patient safety. Agency for Healthcare Research and Quality (AHRQ) 2008. https://www.ahrq.gov/teamstepps/ index.html 
28. Agency for Healthcare Research and Quality (AHRQ). TeamSTEPPS Implementation Guide 2.0. Step 1. Create a Change Team. Last reviewed 3/2014. https://www.ahrq.gov/.../essentials/ implguide.pdf; https://www.ahrq.gov/teamstepps/ instructor/fundamentals/module11/igimplement. htm

29. Denno J, Gannon M. Practical steps to lower blood culture contamination rates in the emergency department. Emerg Nurs Assoc. 2013;39:459-64. https://doi.org/10.1016/j.jen.2012.03.006.

30. Self WH, Speroff T, McNaughton CD, Wright PW, Miller G, Johnson JG, et al. Blood culture collection through peripheral intravenous catheters increases the risk of specimen contamination among adult emergency department patients. Infect Control Hosp Epidemiol. 2012;33:524-6. https://doi.org/10. $1086 / 665319$.
31. Septimus E. Collecting cultures: a clinician guide: https://www.cdc.gov/antibiotic-use/core-elements/ collecting-cultures.html. Accessed 3/21/2020.

32. Mermel LA, Allon M, Bouza E, Craven DE, Flynn P, $\mathrm{O}^{\prime}$ Grady NP, et al. Clinical practice guidelines for the diagnosis and management of intravascular catheter related infection: 2009 update by the Infectious Diseases Society of America. Clin Infect Dis. 2009;49:1-45. https://doi.org/10.1086/599376.

33. Martinez JA, DesJardin M, Aronoff S, Supran S, Nasraway SA, Snydman DR. Clinical utility of blood cultures drawn from central venous or arterial catheters in critically ill surgical patients. Crit Care Med. 2002;30:7-13. https://doi.org/10.1097/ 00003246-200201000-00002. 